\title{
The Impact of Public Law 111-216: Perceptions of U.S. Collegiate Flight Students
}

\author{
Mallory K. Casebolt, Timm J. Bliss, and Chad L. Depperschmidt \\ Oklahoma State University
}

\begin{abstract}
This national research study is the second part of a three-part study examining the perceptions and effects of Public Law 111-216. Part one examined the perceptions of U.S. collegiate flight programs and part three will examine the perceptions of pilots employed with a part 121 U.S. air carrier operator. This research study examined the perceptions of United States collegiate flight students regarding the impact of Public Law 111216 after its implementation to determine how Public Law 111-216 will affect collegiate flight students and the U.S. airline industry. This study was conducted to determine if a relationship exists between collegiate flight students' perceptions of PL 111-216 and the possible effects it may have on collegiate flight students' desires and ambitions to become U.S. commercial pilots and the U.S airline industry. The findings of this research study impact collegiate flight students, collegiate flight programs, and the U.S. airline industry. This research provides collegiate flight programs and the U.S. airline industry insight into flight students' perceptions of PL 111-216. This insight may help forecast future trends in prospective enrollments and retention rates of current students in collegiate flight programs due to the significant increase of unanticipated flight costs. This study has the potential to also provide a vision of future pilot supply. The findings provide an avenue for collegiate flight programs and the U.S. airline industry to address possible areas of concerns as a result of PL 111-216 changes in pilot qualification standards.
\end{abstract}

Since the birth of manned powered flight in 1903, aviation related fatalities and crashes are not new throughout the U.S. It is reported that the first national aviation casualty occurred just five short years after the Wright brothers made their historical powered flight in Kittyhawk (The Wright Brothers First Flight 1903, 2003 para. 2).

After the highly publicized crash of Colgan Flight 3407, also referred to as codeshare Continental Flight 3407, U.S. legislators questioned adequate pilot training qualifications and overall aviation safety in the nation. As an outcome of the deadly 2009 crash and a combination of efforts to decrease the associated risks with flight, the Colgan Flight 3407 tragedy triggered a substantial overhaul of airline safety and pilot qualification. This overhaul was particularly impactful to U.S. collegiate flight students by changing pilot qualification standards.

Colgan Flight 3407 crashed five miles from its intended destination airport in Buffalo, New York. The aircraft, a Bombardier Dash-8 Q400, was approaching the destination airport when its speed became too slow and the aircraft stick shaker automatically pushed forward to keep the aircraft from stalling. The captain immediately initiated the wrong reaction and pulled back on the stick, which caused the aircraft to go into a full aerodynamic stall. Unfortunately, due to pilot error, once the aircraft stalled, the aircraft was never 
recovered by the captain or first officer and crashed into a New York neighborhood. The two pilots, two flight attendants, and 45 passengers aboard the airplane were killed in the crash. Additionally, one person on the ground was killed and the airplane destroyed on impact by destructive forces and post-crash fire (National Transportation Safety Board, 2010 p. 1).

The crash of Colgan Flight 3407 brought immediate attention to the U.S. airline industry, primarily regarding safety concerns. Garrison (2010) explains that Colgan Flight 3407 crash received an unusual amount of media scrutiny; partly, because of what the National Transportation Safety Board's (NTSB) report revealed about the captain and the first officer. The NTSB revealed the flight failed due to the captain's flight control errors, and also commented on the unique lifestyle of the first officer. Garrison (2010) remarked about the first officer's lifestyle, living in Seattle and traveling a long commute across the country for work; while existing on a salary of a little more than $\$ 15,000$ a year. Additional information about the captain and first officer of Colgan Flight 3407 also brought scrutiny to the U.S. airline industry regarding the following aviation safety concerns: fatigue due to long pilot commutes, inadequate training in the cockpit, and insufficient government oversight. Colgan Flight 3407 is a fundamental prompt of the massive overhaul of airline safety and pilot qualification that now affects the entire U.S. airline industry including U.S. collegiate flight students.

After the 2009 fatal crash, family members of the victims of Colgan flight 3407 came together creating unity out of tragedy. The victim's family members formed the group called, Families of Continental Flight 3407. This group operates and maintains a website (3407memorial.com) that shares stories from loved ones, pictures, slideshows, recent news, along with other things pertinent to Colgan Flight 3407. Victim's family members, with support from the U.S. Congress, believed that Colgan Flight 3407 and previous U.S. regional airline crashes could have been avoided with improved aviation safety; emphasizing increased pilot qualification standards.

Extensive national media coverage combined with victim's family members uniting, resulted in political pressure being applied to Congressional representatives. The push was for improved airline safety legislation; predominantly by increasing minimum pilot flight hours and requiring Air Transport Pilot (ATP) certification for first officers. It took family members approximately fifteen months, twenty congressional hearings, and more than forty personal visits to Washington, DC, before President Barack Obama signed Public Law 111- 216 (PL 111-216) into law in August 2010 (Families of Continental Flight 3407, 2013).

\section{Statement of the Problem}

In 2010, President Barack Obama signed the Airline Safety and Federal Aviation Administration Extension Act of 2010, one of the most comprehensive aviation safety regulations, more commonly referred to as Public Law 111-216 or PL 111-216.

Overall, PL 111-216 outlines numerous requirements in an attempt to improve the safety of the American flying public (Families of Continental Flight 3407, 2013). Specifically, Section 216 changes the qualification requirements for all Part 121 pilots; requiring every Part 121 pilot to hold an Airline Transport Pilot (ATP) certificate. This mandatory requirement was implemented three years after PL 111-216 was signed into law in 2010; becoming effective in August 2013.

Prior to PL 111-216 section 216, Part 121 commercial pilots could possess a commercial pilot license with multi-engine and ratings with significantly fewer flight hours (less than 500 earned flight hours) and still be qualified as a first officer for Part 121 air carriers. Also prior to PL 111-216, pilots operating as first officers, under Part 121 carriers, were not required to have earned an ATP certificate. Therefore, as a result of PL 111-216, all first officers are now required to earn considerable more flight hours and an ATP certificate for employment with a U.S. air carrier. These additional flight hours represent a significant financial expense not previously experienced by collegiate flight students. 
Section 217, of PL 111-216, states that an ATP certificate requires a minimum of 1,500 hours of total flight time. However, an exception to these 1,500 hours now exists for collegiate flight students. Students can now earn a restricted-ATP (R-ATP) certificate with only 1,000 hours of total flight time. Even though there is a 500 flight hour reduction from an ATP to a R-ATP. PL 111-216 still requires the collegiate flight student to accumulate several hundred additional flight hours beyond current academic requirements before he/she can sit in the right seat (first officer) of a U.S. air carrier.

Overall, the impact of sections 216 and 217 of PL 111-216 on collegiate flight programs in the U.S. may include: (1) an increase in student flight costs, (2) a decrease in student enrollment and/or student retention issues in collegiate flight programs, (3) a decrease in post-graduate job placements such as first officers, and (4) the increased risk of financial viability of U.S. collegiate flight programs.

A recent published research study (Bjerke and Malott, 2011) concerning PL 111-216 determined that the career progression of aspiring airline pilots could be negatively affected as a result of this new legislation. Other research studies also suggest similar significant concern with PL 111-216. Research by Depperschmidt (2013) found that collegiate aviation training institutions are concerned with increased program and training cost as a result of PL 111-216. Similarly, Depperschmidt, Bliss, and Casebolt (2015) discovered that as a result of the new legislation, collegiate flight students will begin to pursue flight careers (non-US airline or corporate aviation) that are not directly impacted by PL 111-216.

\section{Purpose of the Study}

The purpose of this national research study focused on the impact of PL 111-216 on collegiate flight students, after its implementation, by exploring the influence this law has had on collegiate flight student's perceptions. This study demonstrates if a relationship exists between U.S. collegiate student's perceptions of PL 111-216 and the possible effects it will have on collegiate flight students ambitions to continue to become flight professionals. As well as examining collegiate flight students' perceptions, this national research study examined how their perceptions could affect their professional aspirations. Specifically, this study determined the extent to how PL 111-216 will affect collegiate flight students and the U.S. airline industry after implementation. Soliciting the perceptions of collegiate flight student's regarding PL 111-216 could provide insights for addressing problems for U.S. collegiate flight programs, legislators, academicians, regional airline carriers, and the U.S. aviation industry.

\section{Research Questions}

In order to achieve the purpose of this study the following research questions were formulated to guide this study:

1. How will Public Law 111-216 affect collegiate flight students?

2. How will Public Law 111-216 affect the U.S. airline industry?

\section{Methodology}

To better understand the perceptions of collegiate flight students concerning the effects and challenges associated with PL 111-216, the following research questions were used to guide this study:

1. How will Public Law 111-216 affect collegiate flight students?

2. How will Public Law 111-216 affect the U.S. airline industry? 


\section{Selection and Description of the Research Population}

To answer the two research questions, this study sought the perceptions of U.S. collegiate flight students of four-year public and private universities located in the U.S. which offered comprehensive aviation curriculums, and awarded a bachelor's degree in professional pilot/flight professional. The four-year universities were also institutional members of the University Aviation Association.

In March 2015, the authors requested participation from 17 universities; all meeting the following requirements created by the author's: (1) institutional membership in the UAA, and (2) four-year public or private university offering a comprehensive aviation curriculum awarding a bachelor's degree in professional pilot/flight.

The flight center managers and/or aviation faculty members employed by these universities were contacted by email asking for their willingness and participation in disseminating the research questionnaire to their collegiate flight students. The initial email sent to the flight center managers and/or aviation faculty members explained the academic and professional importance of the study and included instructions in administering the research questionnaire. To participate, each flight center manager and/or aviation faculty member was asked to reply to the email and send the authors their complete contact information including their name and address as well as the approximate number of collegiate flight students currently enrolled in their flight program. After receiving this information, the authors mailed the research questionnaires and a pre-paid postage return envelope to the flight center manager and/or aviation faculty member. All participating flight center managers and/or aviation faculty members were mailed a packet of stapled research questionnaires to distribute, in person, to their collegiate flight students. After two weeks, the authors sent an email reminding the participating flight center managers and/or aviation faculty members to encourage them to return all completed questionnaires in the provided pre-paid postage envelope to the researcher. Within two months, all research questionnaires were returned and analyzed by the authors. Seven of the seventeen invited universities participated in the study resulting in a $41 \%$ overall response rate. From these seven participating universities, a total of 283 collegiate flight students completed the research questionnaire.

\section{Research Questionnaire}

The research questionnaire for this study was developed by the authors. The research questionnaire, The Effect of Public Law 111-216: Perceptions of U.S. Collegiate Flight Students (Appendix) consisted of three specific sections. The first section of the questionnaire generated demographic information identifying collegiate flight students: logged flight hours, flight ratings and/or certifications, financial resources to pay for flight training costs and college tuition, and career/professional aspirations regarding flight. The second section of the research questionnaire listed a series of Likert-scale statements with ordinal measurement pattern options ranging from: (1) Strongly Disagree, (2) Disagree, (3) Agree, and (4) Strongly Agree. For this study, the authors used a 1-4, forced-response, Likert-Scale. The forced-response Likert-scale does not offer a central or neutral choice and forces the respondents to agree or disagree with the statement (Trochim, 2006). The personal information questions and Likert-scale statements intended to gain meaningful insight into collegiate flight students' perceptions related to PL 111-216. The final section was for participants' personal comments. In this section, participants were provided a blank text box at the end of the research questionnaire to provide personal comments regarding the effect PL 111-216 may have on collegiate flight students and the U.S. airline industry. Permission to conduct this study and solicit this research questionnaire was approved by the Institutional Review Board at Oklahoma State University (approval \# ED-15-49).

\section{Limitations of Study}

Although this was a national research study, the findings were limited to the volunteer participation of collegiate flight students currently enrolled in a four-year public or private university offering comprehensive aviation curriculums, awarding a bachelor degree in professional pilot/ flight professional; 
and holding institutional membership in the University Aviation Association. This research study did not include flight students receiving training from two-year public or private educational institutions, as well as non-collegiate flight programs or military flight training programs. Results of this study reflect the responses of 283 participating respondents who were available and willing to complete the research questionnaire.

The double-barreled statements on the Likert-scale caused some interrelation problems associated with the research questionnaire. A double-barreled statement contains more than one question, yet the respondent only has the option to respond to one of the two questions, and cannot indicate which question is being answered. The respondent could agree with one question but not the other, which makes an overall response more difficult. Although the double-barreled statements on the Likert-scale potentially caused some interrelation problems with the research questionnaire, no participants expressed concern in the personal comments on the research questionnaire.

\section{Statistics and Measures}

The Likert-scale statements were analyzed using Cronbach's alpha $(\alpha)$ reliability test to measure internal consistency. To measure internal consistency, Cronbach's $\alpha$ determines how all items on a test are related to all other items and the total test (Gay, Mills, \& Airasian, 2006). George and Mallery (2003) established the following Cronbach's $\alpha$ acceptance scale: " $\geq .9$ - Excellent; $\geq .8$ - Good; $\geq .7$ - Acceptable; $\geq .6$ - Questionable; $\geq .5$ - Poor; and $\geq .5$ - Unacceptable" (p. 231). To analyze the results of this study, all data was input into IBM SPSS software.

\section{Findings}

\section{Demographics}

Participants were asked to identify their total number of flight hours they logged during flight training. Table 1, Collegiate Flight Students Total Logged Flight Hours, indicates that of the N=283, 18\% logged 0- 49 flight hours, 16\% logged 50-99 flight hours, 28\% logged 100-199 flight hours, 20\% logged 200299 flight hours, 10\% logged 300-399 flight hours, and 8\% logged 400 \& over flight hours.

Table 1

Collegiate Flight Students Total Logged Flight Hours

\begin{tabular}{l|l} 
Number of Flight Hours & Percentage of Responses \\
\hline $0-49$ & $18 \% \mathrm{n}=51$ \\
\hline $50-99$ & $16 \% \mathrm{n}=44$ \\
\hline $100-199$ & $28 \% \mathrm{n}=80$ \\
\hline $200-299$ & $20 \% \mathrm{n}=56$ \\
\hline $300-399$ & $10 \% \mathrm{n}=29$ \\
\hline $400 \&$ Over & $8 \% \mathrm{n}=23$ \\
\hline
\end{tabular}

In addition, the research questionnaire asked respondents to identify if they are currently a Certified Flight Instructor (CFI) and logging hours to meet the restricted ATP requirement of 1,000 flight hours. Of the $\mathrm{N}=283$, $(n=41) 15 \%$ of participants identified that they were Certified Flight Instructors, as indicated in Table 2 . 
Table 2

Students Identified as Current Certified Flight Instructors

\begin{tabular}{l|l} 
Response Yes or No & Percentage of Responses \\
\hline Yes & $15 \% \mathrm{n}=41$ \\
\hline No & $85 \% \mathrm{n}=242$ \\
\hline
\end{tabular}

The third demographic question asked participants to identify the percentage of their flight costs that are supported by financial aid (student loans) and/or scholarships. Table 3 shows that a majority of respondents $(56 \%)$ indicated $0-24 \%$ of their flight costs are supported by financial aid (student loans) and or scholarships; whereas, $30 \%$ answered that $75-100 \%$ of their flight costs are supported by financial aid (student loans) and/or scholarships. Only $14 \%$ of students indicated that between $25 \%$ and $74 \%$ of their flight costs were supported by financial aid (student loans) and/or scholarships.

Table 3

Percentage of Flight Cost Support by Financial Aid and/ or Scholarships

\begin{tabular}{l|l}
$\begin{array}{l}\text { Percent of Flight Cost } \\
\text { Support }\end{array}$ & Percentage of Responses \\
\hline $0-24 \%$ & $56 \% n=157$ \\
\hline $25-49 \%$ & $7 \% \quad n=21$ \\
\hline $50-74 \%$ & $7 \% \quad n=20$ \\
\hline $75-100 \%$ & $30 \% n=85$ \\
\hline
\end{tabular}

The last demographic question asked participants to identify their career aspirations regarding flight. Students were given four choices to select from: commercial pilot, military aviator, corporate pilot, and other. Table 4 illustrates participants' career aspirations regarding flight. Over half $(65 \%)$ of the participants indicated their future career aspiration was to become a commercial pilot. Forty-five $(16 \%)$ participants responded that their career aspiration was to fly for a corporation, and only eight percent chose the military as a career path. Participants (11\%) selecting "Other" identified their career aspiration as the following: missionary pilot, aviation attorney, agriculture pilot, pipeline survey pilot, recreational pilot, or test pilot.

Table 4

Career Aspirations Regarding Flight

\begin{tabular}{l|l} 
Career & Percentage of Responses \\
\hline Commercial Pilot & $65 \% \mathrm{n}=185$ \\
\hline Military Aviator & $8 \% \mathrm{n}=22$ \\
\hline Corporate Pilot & $16 \% \mathrm{n}=45$ \\
\hline Other & $11 \% \mathrm{n}=31$ \\
\hline
\end{tabular}

\section{Likert-Scale Statements}

The second section of the research questionnaire explored the personal perceptions of each participating collegiate flight student. Fourteen Likert-scale statements requested participants to indicate their perception of each statement by selecting one of four response options: strongly disagree (SD), disagree (D), agree (A), and strongly agree (SA). 
Table 5, Collegiate Flight Students' Knowledge and Concern of Public Law 111- 216, presents data obtained from three Likert-scale statements revealing participants' perceptions of: (1) student's knowledge of PL 111-216 and its potential effect on collegiate flight students, (2) student's concern of PL 111-216 as a collegiate flight student and (3) student's perception of financial concern of attaining a minimum of 1,000 flight hours required by PL 111-216.

Table 5

Collegiate Flight Students' Knowledge and Concern of Public Law 111-216

\begin{tabular}{l|c|c|c|c}
\multicolumn{1}{c|}{ Likert-Scale Statements } & SD & D & A & SA \\
& & & & \\
\hline I am knowledgeable of PL 111-216 and its potential effect & 24 & 31 & 142 & 86 \\
on collegiate flight students. & $9 \%$ & $11 \%$ & $50 \%$ & $30 \%$ \\
\hline PL 111-216 is of significant concern to me as a collegiate & 14 & 27 & 111 & 131 \\
flight student. & $5 \%$ & $10 \%$ & $39 \%$ & $46 \%$ \\
\hline Attaining the required 1,000 flight hours specified by PL & $6 \%$ & $15 \%$ & $27 \%$ & $52 \%$ \\
$\begin{array}{l}\text { 111-216 is a significant financial concern to me as a } \\
\text { collegiate flight student. }\end{array}$ & & & & \\
\hline
\end{tabular}

Adapted from: Casebolt, Mallory, K. (2015). The Impact of Public Law 111-216: Perceptions of US Collegiate Flight Students. Unpublished doctoral dissertation, Oklahoma State University, Stillwater.

Responding to the Likert-scale statement, "I am knowledgeable of PL 111-216 and its potential effect on collegiate flight students", over three-fourths (80\%) of participants strongly agreed or agreed that they are knowledgeable of PL 111-216 and its potential effects. The remaining 20\% indicated that they were not knowledgeable of PL 111-216. When responding to the Likert-scale statement, "PL 111-216 is of significant concern to me as a collegiate flight student", 242 participants (85\%) strongly agreed or agreed that PL 111216 was a significant concern; whereas, 15 percent of participants' stated that PL 11-216 was not a personal concern. The majority of participants, $79 \%$, strongly agreed or agreed with the statement, "Attaining the required 1,000 flight hours specified by PL 111-216 is a significant financial concern to me as a collegiate flight student". Only 21 percent of participants strongly disagreed or disagreed that the increase of flight hours was a financial concern for them. Agreeing with the majority, one participant commented in the comment section, “It's not just the hourly requirement that's hurting upcoming pilots, it's the $\$ 20$, 000 ground course we're required to take just to qualify for taking the ATP written. The entire law was a reaction to an incident that the ramifications of the law would not have prevented in the first place. The decision to put it into law obviously wasn't made considering how it would affect upcoming pilots." The participant continued by stating, "Sitting in a single engine aircraft watching my students fly for 1,500 hours will not prepare me for the airlines or make me any safer once I get there, if you want us (collegiate flight students) to be safer in large aircraft, enable us cheaper and quicker access to train in them, so we can gain that experience."

Table 6 presents data obtained from four Likert-scale statements involving the participants' perceptions of: (1) student's motivation to earn a Bachelor of Science degree compared to average initial salary for Part 121 first officers, (2) prospective student's enrollment with new flight hour and restricted ATP requirements (3) retention rate of collegiate flight students due to increased flight hours, and (4) increase in current collegiate flight students pursuing other non-professional pilot aviation degrees as a result of PL 111216. 
Table 6

Collegiate Flight Students' Motivation and Employment Perceptions of Public Law 111- 216

\begin{tabular}{l|c|c|c|c}
\multicolumn{1}{c|}{ Likert-Scale Statements } & SD & D & A & SA \\
& & & & \\
\hline $\begin{array}{l}\text { The additional flight hours required by PL 111-216 } \\
\text { affects my motivation to earn a Bachelor of Science } \\
\text { flight degree compared to the starting salary for }\end{array}$ & $7 \%$ & $19 \%$ & $37 \%$ & $37 \%$ \\
$\begin{array}{l}\text { First Officers employed by Part 121 air } \\
\text { carriers is only \$25,000. }\end{array}$ & & & & \\
\hline $\begin{array}{l}\text { PL 111-216 (restricted ATP and increased number of flight } \\
\text { hours) will adversely affect the recruitment of prospective }\end{array}$ & $3 \%$ & $14 \%$ & $44 \%$ & $39 \%$ \\
students enrolling in collegiate flight programs. & 8 & 62 & 119 & 94 \\
\hline $\begin{array}{l}\text { PL 111-216 will have a negative effect on the retention } \\
\text { rate of collegiate flight students due to the increased } \\
\text { mandatory flight hours (restricted ATP requires 1,000 }\end{array}$ & $3 \%$ & $22 \%$ & $42 \%$ & $33 \%$ \\
flight hours). & & & & 104 \\
\hline $\begin{array}{l}\text { PL 111-216 will cause an increase in current collegiate } \\
\text { flight students pursuing other non-professional pilot } \\
\text { aviation degrees (management, avionics, etc.). }\end{array}$ & $5 \%$ & $23 \%$ & $44 \%$ & $28 \%$ \\
\hline
\end{tabular}

Adapted from: Casebolt, Mallory, K. (2015). The Impact of Public Law 111-216: Perceptions of US Collegiate Flight Students. Unpublished doctoral dissertation, Oklahoma State University, Stillwater.

The majority of participants (74\%) either strongly agreed or agreed with the statement, "The additional flight hours (minimum of 1,000 flight hours) required by PL 111-216 affects my motivation to earn a Bachelor of Science flight degree, since the average starting salary for first officers employed by Part 121 air carriers is only $\$ 25,000$ ". The remaining participants (26\%) strongly disagreed or disagreed with the statement. An overwhelming 83 percent of participants strongly agreed or agreed with the statement, "PL 111-216 (restricted ATP and increased number of flight hours) will adversely affect the recruitment of prospective students enrolling in collegiate flight programs"; while 17 percent of students strongly disagreed or disagreed that the R-ATP will affect the recruitment of prospective collegiate flight students.

Regarding the statement, "PL 111-216 will have a negative effect on the retention rate of collegiate flight students due to the increased mandatory flight hours (restricted ATP requires 1,000 flight hours)", the majority of participants $(75 \%)$ strongly agreed or agreed that this new legislation will impact the retention rate of collegiate flight students. In regards to the retention rate, one participant indicated, "My two best friends dropped out of flight because of this. I also almost did. School is already over $\$ 100,000$ and starting jobs make very little money, as do flight instructors. This is quantity over quality." Over seventy percent of participating students strongly agreed or agreed with the statement, "PL 111-216 will cause an increase in current collegiate flight students pursuing other non-professional pilot aviation degrees (management, avionics, etc.)”, with one student indicating, “....as a student I decided not to pursue a career in flying due to PL 111-216. I felt that 1,000 hours was a financial hardship that was not worth it. I also feel that the new rule no longer encourages quality training, it encourages flight time no matter the quality." 
Participants were also asked about their perceptions regarding whether their institution's aviation department should be concerned about PL 111-216 and the possibility of a U.S. pilot shortage due to the requirement of the R-ATP and/or less students enrolling in collegiate flight programs. Table 7, Collegiate Flight Students' Perceptions of Institutional Concern and Pilot Shortage, details the responses regarding these two concerns of PL 111-216.

Table 7

Collegiate Flight Students' Perceptions of Institutional Concern and Pilot Shortage

\begin{tabular}{l|c|c|c|c}
\multicolumn{1}{c|}{ Likert-Scale Statements } & SD & D & A & SA \\
\hline PL 111-216 should be a primary concern of the & 8 & 38 & 108 & 129 \\
aviation department at my college/university. & $3 \%$ & $13 \%$ & $38 \%$ & $46 \%$ \\
\hline PL 111-216 will cause a US pilot shortage due & 6 & 49 & 113 & 115 \\
to the increase in required flight hours and/or the & $2 \%$ & $17 \%$ & $40 \%$ & $41 \%$ \\
decrease in students enrolling in a collegiate flight program. &
\end{tabular}

Adapted from: Casebolt, Mallory, K. (2015). The Impact of Public Law 111-216: Perceptions of US Collegiate Flight Students. Unpublished doctoral dissertation, Oklahoma State University, Stillwater.

When asked if, "PL 111-216 should be a primary concern of the student's aviation department", 84 percent of participants strongly agreed or agreed; similarly, $81 \%$ of the participating students strongly agreed or agreed that, "PL 111-216 will cause a pilot shortage in the U.S. due to the increase in required flight hours and/or a decrease in collegiate flight student enrollments". One participant stated on their comment section, "Smaller regional carriers will encounter a shortage of pilots in the next five years."

Table 8 presents data identifying participants' perceptions of the restricted ATP and the effect it will have on first officers. The responses from the Likert statement, "A 'restricted ATP' (minimum 1,000 flight hours) should be required for a first officer to be employed with a Part 121 U.S. air carrier operator", indicated that the majority of participants (58\%) strongly disagreed or disagreed that a R-ATP should be required for a first officer; however, when asked to respond to the statement, "restricted ATP' requirement in PL 111-216 will make newly employed first officers more qualified and capable pilots", a majority of participants (54\%) strongly agreed or agreed that the R-ATP will make them more qualified and capable first officers. Regarding these two statements, one of the participants indicated, "1,000 hours will make a more capable FO, however with financial issues involved it is definitely an incentive to discontinue flight training as I've had many close friends go that route. I believe 1,000 hours is a lot of time and even though the law was designed to prevent pilot error, there will always be external/internal pressures to cause pilot error because we are all human. Also the fact that most flight students were not born rich and school is expensive, many of us do not look forward to $\$ 25,000$ a year and expect to pay off loans as well as bills, food expenses, etc. There are other ways to become a more effective pilot, such as pairing an FO with an experienced captain because really an FO learns from the captain." 
Table 8

Collegiate Flight Students Perceptions of Restricted ATP

\begin{tabular}{l|c|c|c|c}
\multicolumn{1}{c|}{ Likert-Scale Statements } & SD & D & A & SA \\
\hline $\begin{array}{l}\text { A “restricted ATP" (minimum 1,000 flight hours) } \\
\text { should be required for a First Officer to be employed }\end{array}$ & $21 \%$ & $37 \%$ & $31 \%$ & $11 \%$ \\
with a Part 121 US air carrier operator. & & & & \\
\hline $\begin{array}{l}\text { The "restricted ATP" requirement in PL 111-216 will } \\
\text { make newly employed First Officers more qualified } \\
\text { and capable pilots. }\end{array}$ & $18 \%$ & $28 \%$ & $41 \%$ & $13 \%$ \\
\hline
\end{tabular}

Adapted from: Casebolt, Mallory, K. (2015). The Impact of Public Law 111-216: Perceptions of US Collegiate Flight Students. Unpublished doctoral dissertation, Oklahoma State University, Stillwater.

Lastly, three Likert-Scale statements asked participants if PL 111-216 will create a safer flight environment, will decrease the number of fatal accidents due to pilot error, and will have a significant impact on the overall U.S. commercial aviation industry. Table 9, Collegiate Flight Students' Perceptions of Overall Impact of PL 111-216, provides data obtained from these three statements.

Table 9

Collegiate Flight Students' Perceptions of Overall Impact of PL 111-216

\begin{tabular}{l|c|c|c|c}
\multicolumn{1}{c|}{ Likert-Scale Statement } & SD & D & A & SA \\
\hline New regulations as a result of PL 111-216 will create a & 41 & 91 & 119 & 32 \\
safer environment for Part 121 US air carrier operators. & $15 \%$ & $32 \%$ & $42 \%$ & $11 \%$ \\
\hline Fatal accidents involving US airlines (due to "pilot & 62 & 123 & 79 & 19 \\
error") will decrease as a result of PL 111-216. & $22 \%$ & $43 \%$ & $28 \%$ & $7 \%$ \\
\hline $\begin{array}{l}\text { Overall, the effects of PL 111-216 will have a } \\
\text { significant impact on pilots, as well as the entire US } \\
\text { airline industry. }\end{array}$ & $6 \%$ & $7 \%$ & $37 \%$ & $54 \%$ \\
\hline
\end{tabular}

Adapted from: Casebolt, Mallory, K. (2015). The Impact of Public Law 111-216: Perceptions of US Collegiate Flight Students. Unpublished doctoral dissertation, Oklahoma State University, Stillwater.

Approximately half (53\%) of the participants strongly agreed or agreed with the statement, "New regulations as a result of PL 111-216 will create a safer environment for Part 121 U.S. air carrier operators". Sixty-five percent of students strongly disagreed or disagreed with the statement, "Fatal accidents involving U.S. airlines (due to "pilot error") will decrease as a result of PL 111-216". One participant indicated that, "Fatal accidents could happen for any pilot even if he/she had one million hours of flying experience." And yet, an overwhelming ninety-one percent of participants strongly agreed or agreed that "the effects of PL 111216 will have a significant impact on pilots, as well as the entire U.S. airline industry".

Using data from $\mathrm{N}=283$ participants, the internal reliability of the questionnaire resulted in an alpha coefficient of .644. Given the previous scale outlined by George and Mallery (2003), the internal reliability of the questionnaire was rated as questionable. 


\section{Discussions}

Based on the overall perceptions of collegiate flight students, PL 111-216 was determined to be a primary concern of collegiate flight students, collegiate flight programs, and the U.S. airline industry. When participants were asked to identify their career aspirations regarding flight, over $65 \%$ of students indicated they sought to become commercial pilots; however, many of the participants expressed their concern with the additional time and finances (flight costs) involved in obtaining the new R-ATP certificate and the amount of flight hours associated with PL 111-216.

Overall, collegiate flight students perceived that PL 111-216 will affect both collegiate flight students and the U.S. airline industry. According to the results from 283 collegiate flight students, PL 111-216 will affect the collegiate flight environment, collegiate flight students, students pursuing careers as Part 121 commercial pilots, and the U.S. airline industry.

Collegiate flight students' primary concern was the financial difficulties as a result of PL 111-216. Students perceive that PL 111-216 will create an issue for students obtaining a Bachelor's degree concerning paying for flight training cost and the time it takes to reach the required flight minimums. As a result of high tuition, flight costs, and the availability of time, students also perceived that PL 111-216 will affect the ambition of remaining motivated to complete their college degree.

Students unable to meet the flight hour requirements due to finances or the increased amount of time it takes to reach the 1,000 flight hour minimum could be a concern to the U.S. airline industry. Sixty-one percent of students surveyed identified that they have logged less than 200 flight hours which represents a substantial difference between the previous requirement of a certified commercial pilot certificate and the new 1,000 flight hours required for an R-ATP certificate.

Students also believe that as a result of PL 111-216 there will be a decrease in collegiate flight student enrollment and/or retention in collegiate flight programs.

Collegiate flight students also perceive that the implementation of increased flight hours and R-ATP certificate will not create a safer environment for commercial aviation or decrease fatal accidents due to pilot error. Because the perceived direct effect on collegiate flight students, the U.S. airline industry will also be affected by PL 111-216 which could be shown in numerous possibilities. These possibilities could include a decrease in regional service, a decrease in qualified pilots to fill retirement gaps, and a decrease of collegiate aviators to make up for military aviators staying in the service.

Historically, the U.S. airline industry obtains its pilot supply from sources such as collegiate flight programs, trained military pilots, and civilian sources. "Until the 1990s, roughly 90 percent of the pilots hired by major US carriers came from the U.S. military. Today however, hiring percentage have nearly reversed due to military active duty training commitments rising from six to almost twelve years" (Duggar, Smith, and Harrison, 2009, p. 2). To hold on to its trained pilots, the military has offered incentive programs such as wage increases, signing bonuses, and retirement packages; thereby contributing to the decrease of military pilots transitioning into commercial airline service. The result of a decrease in military pilots entering commercial service leaves civilian sources such as collegiate flight programs as the bulk of future professional pilot replacements to fill any anticipated pilot shortages. The military keeping qualified pilots longer creates an increased need for qualified collegiate flight students that meet the new requirements set forth by PL 111-216. If collegiate flight students that identified their career aspirations to become a commercial pilot are unable to meet the new R-ATP certification requirements, the U.S. airline industry could suffer professional pilot replacement problems regarding future pilot shortages. 
According to the perceptions of participating collegiate flight students, since the majority of the U.S. commercial pilot supply is now coming from the collegiate flight environment, PL 111-216 creates a flight time and financial issue for students which could result in a student's decision to pursue other college degree options. If collegiate flight students no longer pursue professional pilot degrees or aviation related degrees' it could persuade collegiate flight programs to reevaluate their flight cost and could create a new financial dynamic for the collegiate flight program.

The results collected from this national study indicated $91 \%$ of collegiate flight students strongly agree or agree that overall the effects of PL 111-216 will have a significant impact on pilots, as well as the entire U.S. airline industry. Overall, collegiate flight students perceived that PL 111-216 will affect collegiate flight students and the U.S. airline industry. According to 283 collegiate flight students, PL 111-216 will affect the collegiate flight environment, collegiate flight students, students pursuing careers as Part 121 commercial pilots, and the U.S. airline industry.

\section{Recommendations}

Based on the findings and conclusions of this study, the author's offer the following recommendations.

Collegiate Flight students should familiarize and educate themselves on the new qualification requirements and all pertinent information related to PL 111-216, since 80\% of responding students agreed the new 1,000 flight hour requirement is a significant financial concern. Students should consider the time, commitment, and financial aspect it takes to obtain an R-ATP certificate with the minimum requirement of 1,000 flight hours. Students should also take into consideration how they plan to obtain the 1,000 flight hour minimum required to obtain an R-ATP certificate. While considering time, commitment, and finances students should also consider the average starting salary for an entry level position as a first officer employed by a Part 121 commercial carrier compared to the average tuition cost to complete a four-year bachelor degree in flight.

Seventy-five percent of students believe that PL 111-216 will have a negative effect on the retention rate of collegiate flight students due to the increase in mandatory flight hours. Seventy-two percent of students believe PL 111-216 will cause an increase in current collegiate flight students pursuing other nonprofessional pilot aviation degrees. Therefore, collegiate flight programs need to make efforts, to make flight cost more affordable for collegiate flight students. Collegiate flight programs should take into consideration the cost for the average student to finish a Bachelor degree in flight with the new flight hour minimums. This may allow programs to make adjustments to encourage students to complete their degree. Although, each program is different and has different flight cost and degree requirements, each collegiate flight program could provide more financial aid through the college/university or increase the availability of scholarships. If collegiate flight programs can adjust for high flight cost experienced by collegiate flight students it can help deter students pursuing other non-flight related degrees.

Ninety-one percent of collegiate flight students indicated that PL 111-216 will have a significant impact on pilots as well as the entire U.S. airline industry. Although PL 111-216 is a fairly new legislation, the U.S. aviation industry should examine any decrease in coming years in qualified pilots or any negative effects on the industry as a result of PL 111-216. If the industry begins to see any problems with pilot shortage because of lack of collegiate flight students entering the future pilot pool, perhaps aviation stakeholders can present the problem to congress to reconsider the amount of flight hours required by PL 111-216 to obtain an R-ATP. 


\section{Recommendations for Further Research}

Further research studies are needed to determine if collegiate flight students receive outside financial support from parents or other sources for collegiate flight cost other than examples listed on the research survey: financial aid, student loans, and/or scholarships. Research should be conducted that will gather information on specifically how the majority of students (56\%) that identified $0-24 \%$ of flight cost are supported by financial aid, scholarships, and or student loans support flight cost. Results from the research could determine the significance of student financial resources and its potential effect to a perceived decline in future pilot numbers and effects on collegiate flight students.

A further study is recommended to explore the perceptions of the U.S. airline industry regarding PL 111-216. This research study should seek to answer if experts within the U.S. airline industry perceive any problems as a result of PL 111-216, specifically involving a decline in qualified pilots from collegiate flight programs. The study should attempt to seek if the U.S. airline industry perceives that PL 111-216 will create a safer environment for commercial aviation in the U.S., if PL 111-216 will reduce pilot error related fatal accidents, and if the R-ATP will make newly employed first officers more qualified and capable pilots. This type of research could benefit from personal interviews from industry leading experts and aviation professionals. Answers to these questions could offer a comprehensive explanation regarding the perceptions of the U.S. airline industry.

As another recommendation for future research, the majority of respondents indicate negativity to PL 111-216, its affects to them and the industry. Research that identifies what changes to PL 111-216 would improve these issues would be beneficial.

The authors believe future research is needed and would be beneficial to examine and calculate the average financial cost as well as the average time it takes a collegiate flight student to meet the new requirements set forth by PL 111-216. This information would be beneficial in determining any further issues with PL 111216.

Since only two years have passed since the enactment of PL 111-216 at the time of this study, future research should reevaluate these same issues after five or ten years. This study gathered the initial responses and reaction of effects from new legislation and student perceptions may change over time as students and collegiate flight programs adjust and adapt to this issue. 


\section{References}

Bjerke, E. \& Malott, D. (2011). Impacts of public law 111-216: will the flight instructor career path remain a viable option for aspiring airline pilots? Collegiate Aviation Review, 29 (1), 1-9.

Byrnes, K. (2015, December 5). Seize the day - AOPA. Retrieved from https://www.aopa.org/news-andmedia/all-news/2015/december/flight-training-magazine/seize-the-day

Depperschmidt, C.L. (2013). Public Law 111-216: Effects of new legislation on collegiate aviation flight training programs. Collegiate Aviation Review, 31 (1), 1-16.

Depperschmidt, C.L., Bliss, T.J., \& Casebolt M.K. (2015). The Effect of Public Law 111-216 on Collegiate Flight Programs: Perceptions of Aviation Faculty and Flight Center Personnel. Collegiate Aviation Review 33, (2) 53-65.

Duggar, J. W., Smith, B. J., \& Harrison, J. (2009). International supply and demand for U. S. trained commercial airline pilots. Journal of Aviation Management and Education, 2

Casebolt, Mallory, K. (2015). The Impact of Public Law 111-216: Perceptions of US Collegiate Flight Students. Unpublished doctoral dissertation, Oklahoma State University, Stillwater.

Families of Continental Flight 3407. (2013). Retrieved from http://3407memorial.com/ index.php/home

Garrison, P. (2010, May 27). Aftermath: the mystery of Colgan 3407. Flying Magazine. Retrieved fromhttp://www.flyingmag.com/safety/accident-investigations/ aftermathmystery-colgan-3407\#MrTCKx5hMbdKyGmU.99

Gay, L.R., Mills, G.E., \& Airasian, P. (2006). Educational Research: Competencies for Analysis and Applications (8th Ed.). Upper Saddle River, New Jersey: Pearson Prentice Hall.

George, D., \& Mallery, P. (2003). SPSS for Windows step by step: A simple guide and reference. 11.0 update (4th ed.). Boston, MA: Allyn \& Bacon.

Lomax, R. G., \& Hahs-Vaughn, D. L. (2012). An introduction to statistical concepts (9th ed.). New York, NY: Routledge.

National Transportation Safety Board. (2010, February 2). Aviation accident report AAR- 10-01. Retrieved from http://www.ntsb.gov/investigations/AccidentReports /Pages/AAR1001.aspx

University of Washington. (2010). Reporting results of common statistical tests in APA format. Retrieved from http://web.psych.washington.edu/writingcenter/writing guides/pdf/stats.pdf

The Wright Brothers First Flight, 1903. (2003). Retrieved from http://eyewitnesstohistory.com/wright.htm

Trochim, Wiliam M.K. (2006). Research Methods Knowledge Base. Retrieved from http://www.socialresearchmethods.net/kb/scallik.php 


\section{Appendix}

\section{Research Questionnaire}

\section{The Effect of Public Law 111-216: Perceptions of US Collegiate Flight Students}

Please provide all requested information. Your responses will be kept confidential.

\section{Overview of Public Law 111-216}

In 2010, the US Congress passed a bill titled the "Airline Safety and Federal Administration Extension Act of 2010" requiring first officers in FAR Part 121 operations to hold an Airline Transport Pilot (ATP) certificate requiring a minimum of 1,500 flight hours. This bill, which was signed into law as Public Law 111-216, gave US airlines three years to comply with this new provision, so it took effect on August 2, 2013.

Accordingly, pilots not holding an ATP by this 2013 deadline would not be permitted to fly for an air carrier in Part 121 operations. FAA recently enacted a rule which allows for some reduced flight time requirements and the creation of a new type of certificate known as a "restricted ATP." A "restricted" ATP certificate will require the pilot to have reached age 21 (versus age 23 for an "unrestricted" ATP), and a minimum flight experience of 1,000 hours for pilots who have completed a professional pilot curriculum from an accredited college or university.

\section{Collegiate Flight Students Characteristics}

1. Approximately how many total flight hours have you logged?
[ ] 0-49
[ ] 100-199
[ ] 300-399
[ ] 50-99
[ ] 200-299
[ ] 400 \& Over

2. Are you currently a Certified Flight Instructor; logging hours to meet the "restricted ATP requirement" of 1,000 flight hours?

[ ] Yes

[ ] No

3. What percentage of your flight costs are supported by financial aid (student loans) and/or scholarships?
[ ] $0-24 \%$
[ ] $50-74 \%$
[ ] $25-49 \%$
[ ] $75-100 \%$

4. What is your career aspiration regarding "flight"?
[ ] Commercial Pilot
[ ] Corporate Pilot

[ ] Military Aviator

[ ] Other 


\section{Collegiate Flight Students Perceptions of Public Law 111-216}

Please indicate your perceptions using the following scale:

$\mathrm{SD}=$ Strongly Disagree, $\mathrm{D}=$ Disagree, $\mathrm{A}=$ Agree, or $\mathrm{SA}=$ Strongly Agree

I am knowledgeable of PL 111-216 and its potential effect on collegiate flight students.

\begin{tabular}{|c|c|c|c|}
\hline SD & $\mathrm{D}$ & A & $\mathrm{SA}$ \\
\hline [ ] & [ ] & [ ] & [ ] \\
\hline $\mathrm{SD}$ & $\mathrm{D}$ & A & SA \\
\hline [ ] & [ ] & [ ] & [ ] \\
\hline SD & $\mathrm{D}$ & A & SA \\
\hline [ ] & [ ] & [ ] & [ ] \\
\hline SD & $\mathrm{D}$ & A & $\mathrm{SA}$ \\
\hline [ ] & [ ] & [ ] & [ \\
\hline
\end{tabular}

The additional flight hours (minimum of 1,000 flight hours) required by PL 111-216 affects my motivation to earn a Bachelor of Science flight degree, since the average starting salary for First Officers employed by Part 121 US air carriers is only $\$ 25,000$.

PL 111-216 (restricted ATP and increased number of flight hours) will adversely affect the recruitment of prospective students enrolling in collegiate flight programs.

PL 111-216 will have a negative effect on the retention rate of collegiate flight students due to the increased in mandatory flight hours (restricted ATP requires 1,000 flight hours).

PL 111-216 will cause an increase in current collegiate flight

$$
\text { SD }
$$

D $\quad$ A $\quad$ SA

Attaining the required 1,000 flight hours specified by PL 111216 is a significant financial concern to me as a collegiate flight student.

students pursuing other non- professional pilot aviation degrees (management, avionics, etc.). 
Please indicate your perceptions using the following scale:

$\mathrm{SD}=$ Strongly Disagree, $\mathrm{D}=$ Disagree, $\mathrm{A}=$ Agree, or SA=Strongly Agree

PL 111-216 should be a primary concern of the aviation department at my college/university.

PL 111-216 will cause a pilot shortage in the US due to the increase in required flight hours and/or the decrease in students enrolling in a collegiate flight program.

A “restricted ATP" (minimum 1,000 flight hours) should be required for a First Officer to be employed with a Part 121 US air carrier operator.

The "restricted ATP" requirement in PL 111-216 will make newly employed First Officers more qualified and capable pilots.

New regulations as a result of PL 111-216 will create a safer environment for Part 121 US air carrier operators.

Fatal accidents involving US airlines (due to "pilot error") will decrease as a result of PL 111-216.

Overall, the effects of PL 111-216 will have a significant impact on pilots, as well as the entire US airline industry.

\begin{tabular}{|c|c|c|c|}
\hline SD & $\mathrm{D}$ & A & SA \\
\hline [ ] & {$[\quad]$} & [ ] & [ ] \\
\hline SD & $\mathrm{D}$ & A & SA \\
\hline [ ] & [ ] & [ ] & [ ] \\
\hline SD & $\mathrm{D}$ & A & SA \\
\hline [ ] & [ ] & [ ] & [ ] \\
\hline SD & $\mathrm{D}$ & A & SA \\
\hline [ ] & {$[\quad]$} & [ ] & [ ] \\
\hline $\mathrm{SD}$ & $\mathrm{D}$ & A & SA \\
\hline [ ] & [ ] & [ ] & [ ] \\
\hline SD & $\mathrm{D}$ & A & SA \\
\hline [ ] & [ ] & [ ] & [ ] \\
\hline SD & $\mathrm{D}$ & A & SA \\
\hline ] & [ ] & [ ] & [ \\
\hline
\end{tabular}

SA

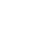

